\title{
MONTEIRO LOBATO: UM JORNALISTA MULTIFACETADO
}

\author{
BEDÊ, Ana Luiza Reis ${ }^{1}$
}

\begin{abstract}
RESUMO: O trabalho do editor revolucionário, do escritor de sucesso e do empreendedor despertou maior interesse dos estudiosos e pesquisadores e deixou na sombra o Monteiro Lobato jornalista. Neste artigo, procuramos resgatar essa faceta do autor de Urupês mostrando como sua relação com os jornais revela tanto um diletante "sapo de redação", quanto um crítico literário e de artes plásticas de envergadura. Durante décadas, Monteiro Lobato colaborou com revistas e jornais abordando os mais diferentes assuntos. Embora errática, sua atividade como jornalista desencadeou polêmicas memoráveis na história da literatura e das artes brasileiras como seu artigo "Paranóia ou mistificação" (1917) para $O$ Estado de São Paulo.
\end{abstract}

PALAVRAS-CHAVE: imprensa, crítica, pré-modernismo, O Estado de São Paulo

\section{MONTEIRO LOBATO: UN JOURNALISTE AUX MULTIPLES FACETTES}

\begin{abstract}
RÉSUMÉ: Le travail de l'éditeur révolutionnaire, de l'écrivain à succès et de l'entrepreneur a éveillé un plus grand intérêt des chercheurs et a laissé dans l'ombre Monteiro Lobato journaliste. Dans cet article, nous cherchons de recouvrer cette facette de l'auteur d'Urupês, en essayent de montrer comment sa relation avec les journaux révèlle-t-elle aussi bien un dilettante "sapo de redação », qu'un critique littéraire et des arts plastiques de grande envergure. Pendant des années, Monteiro Lobato a collaboré dans plusieurs revues et journaux en abordant différents sujets. Tout en étant erratique, son activité comme journaliste a déclenché des polémiques mémorables dans l'histoire de la littérature et des arts brésiliens comme dans son article «Paranoïa ou mystification » pour le journal O Estado de São Paulo.
\end{abstract}

MOTS-CLEFS: presse critique, pré-modernisme, O Estado de São Paulo

\footnotetext{
${ }^{1}$ Pós-doutora em literatura francesa - Université de Paris IV-Sorbonne. 


\section{INTRODUÇÃO}

Começaram cedo as contribuições de Monteiro Lobato para jornais e revistas, muito antes de tornar-se célebre como contista e do sucesso fragoroso de A menina do narizinho arrebitado em 1920. De fato, tanto suas colaborações para o jornal da faculdade e para periódicos do interior paulista, lidos apenas pelos habitantes locais, até seus artigos para O Estado de São Paulo revelam a um tempo o espírito inquieto e polêmico do jornalista, assim como sua inclinação para debates e questionamentos.

Em seus numerosos artigos, vislumbramos um autor multifacetado, capaz de escrever com paixão ora sobre uma produção da Disney, um livro de poesias, ora sobre o petróleo, questões agrícolas ou problemas sanitários. Seus textos primavam pela objetividade, pela linguagem enxuta, por um profundo espírito crítico - sempre bem argumentado - e pelas alternativas que propunha. Além disso, não hesitava em dar asas à sua criatividade, alguns artigos são recheados de diálogos, em outros imperam uma sinceridade perturbadora. Podemos presumir que suas contribuições serviram para alavancar a venda de muitos periódicos Brasil afora.

\section{O FAZ-TUDO DO JORNALISMO}

Em sua experiência extensa e rica como jornalista, Lobato coleciona histórias dignas de suas obras fictícias. É conhecida, por exemplo, sua colaboração no jornal O Minarete do amigo Benjamim Pinheiro. O jornalzinho, de quatro páginas apenas, fora criado para fazer oposição ao prefeito e à Câmara municipal de Pindamonhangaba e as seções eram assinadas pelos antigos amigos da faculdade como Lobato, Godofredo Rangel, Tito Franco e Ricardo Gonçalves. Todos empregavam pseudônimos e sentiam-se à vontade para escrever os maiores absurdos. Em geral, Pinheiro solicitava a Lobato artigos condenando alguma ação do governo, culpando o partido situacionista pela alta do preço da carne ou pelas goteiras na sede da prefeitura. Além desses artigos de fundo, o amigo taubateano encarregava-se tanto de textos de cunho mais filosófico, como igualmente de crônicas abrangendo diferentes assuntos do cotidiano. De sua pena vinham até notas sobre moda feminina. Em carta a Rangel de $1^{\circ}$ de março de 1905, pergunta: "Tens 


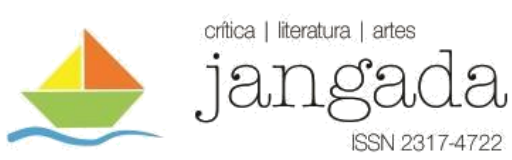

lido o Minarete? As primeiras páginas dos últimos números são totalmente minhas. Apareça por lá.” (LOBATO, 2010, p. 89).

A propósito, em parceria com Rangel, Lobato publica no $O$ Minarete $O$ Queijo de Minas ou História de um Nó cego, romance no qual prometem "várias mortes trágicas". Também para esse pequeno jornal oposicionista, convida o romancista mineiro para uma empreitada a seis mãos:

O Boiadeiro antropófago, por Pinheiro, Rangel e Hélio! Nem plano, nem escola. Cenas obrigatórias: uma antropofagia, dois amores, um incêndio, duas ou três mães que não encontram a filha; e em vez do Dedo de Deus no fim, o Dedo do Ouro esmagando a Inocência e a Virtude! Coisa de derrancar Pindamonhangaba e fazer que aumentem as devoluções do Minarete. Cumpre desasnar o burguês. (LOBATO, 2010, p. 117)

Hélio Bruma era um dos inúmeros pseudônimos de Lobato. Segundo o autor, os leitores do periódico acreditariam, assim, na existência de uma robusta equipe de redatores. Essas brincadeiras de jovens aspirantes a escritores e jornalistas improvisados contribuíram para a reflexão sobre a relação do escritor com o leitor, para discutir questões ligadas à literatura de entretenimento, para pensar sobre a importância de corresponder às expectativas daqueles que sustentavam o jornal. N'O Minarete, Lobato e seus amigos atendiam às solicitações do editor, nos aspectos políticos, mas nem sempre agradavam à clientela correspondendo à sua necessidade de evasão. Os jornais menores serviam como laboratório para os futuros escritores, o trecho seguinte de carta a Rangel de 2 de junho de 1909 é eloquente: "P.S. Insistência de última hora: publicarmos no Minarete os contos à medida que os escrevemos. Será uma espécie de primeira prova tipográfica.” (LOBATO, 2010, p. 197). Lobato chegou a afirmar que nunca conhecera um diretor de jornal tão passivo como o Benjamim. O grupo de amigos do $O$ Minarete também contribuiu com $O$ Combatente “jornaleco de pegar anúncios" (CAVALHEIRO, 1962, p. 68), esse jornal era mantido pelo funcionário do correio Oscar Breves: 


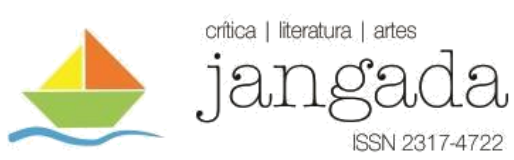

Assim como Lobato punha e dispunha de Benjamim, Ricardo mandava e desmandava no Breves. Não satisfeito com as páginas de "O Minarete", o grupo do "Cenáculo" tomou de assalto "O Combatente". E liderados por Tito Franco, tanto fizeram, que o jornal acabou fechado pela Polícia. Pois enquanto o jornalzinho de Pinda se limitava a desovar literatura ou combater impessoalmente a política local, no "O Combatente" levavam o tempo todo a "serrar figuras da mocidade elegante de São Paulo.” (Idem, p. 68)

Nessa mesma época, Lobato escreve para o jornal Onze de agosto do grêmio acadêmico da Faculdade de Direito. Também colaborou com $O$ Povo de Caçapava. A medida que os anos passavam, crescia o envolvimento de Lobato com os mais diferentes jornais e revistas. No dia 23 de julho de 1909, escreve a Rangel: "P.S. Ando a colaborar no Fon- Fon. O que aparece lá assinado H.B. é meu. Desenho e caricaturas.” (LOBATO, 2010, p. 209). Em 3 de agosto de 1909, conta ao escritor mineiro: "Estou escrevendo na Tribuna, de Santos, jornal cor-de-rosa, a 10 mil-réis o artigo. Mandei para lá hoje o Bocatorta." (Idem p. 210) e em de 2 de setembro de 1909, acrescenta:

O meu negócio com a Tribuna é pequeno: cinco artigos por mês. Talvez também entre na Gazeta de Notícias [...] Mas o negócio mais importante em que ando às portas é a compra, por um grupo, dum jornal de São Paulo e eu iria para o comando literário. (Ibidem, 2010, p. 219)

Para os jornais, Lobato queria escrever só quando tivesse vontade, não lhe agradava a ideia de prazos para entregar artigos, por isso, aprazia-lhe a condição de freelance. Embora sua colaboração com jornais fosse imensa, estendendo-se por vários anos e abrangendo diferentes periódicos, a relação de Lobato com a imprensa lembrava a de um diletante:

Fernando Morais ainda menciona o jornalista na biografia que escreveu a respeito de Assis Chateaubriand, revelando sua participação no grupo do magnata durante a década de 1920. Afirma, porém, que não obstante admirasse o trabalho de Monteiro Lobato, Chateaubriand queixava-se "da falta de assiduidade e do comportamento boêmio do escritor paulista", que mantinha, já em 1927, a mesma fixação pelo ambiente das redações. 


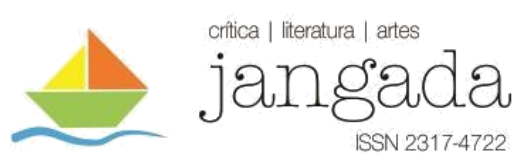

Conforme o registro de Morais, Lobato aparecia n'O jornal - com o qual colaborou regularmente por mais de um ano- para entregar sua coluna, e ali ficava, horas e horas, conversando e "cavaqueando com os colegas" (ASSIS, 2014, p. 306).

Em 1918, já com nome conhecido no meio jornalístico, mantinha seu propósito de contribuir somente quando tivesse uma boa ideia, mas frequentava regularmente a sede de $O$ Estado de São Paulo onde discutia as notícias do dia com os amigos, filava o café, era "sapo de redação"2. Eis que a cidade é surpreendida pela gripe espanhola, acometendo vários jornalistas, muitos do alto escalão. Diariamente Lobato recebia a notícia de algum redator que “caiu”, expressão utilizada para os cidadãos contaminados pelo vírus da gripe. Após várias baixas entre os principais nomes do jornal, o Estado corria o risco de não sair. Foi então que da noite para o dia, Monteiro Lobato tomou a iniciativa de coordenar tudo e até mesmo de escrever o editorial. Para a empreitada, contava com a ajuda de Filinto Lopes. Enquanto este se encarregava de receber as pessoas, Lobato despachava o expediente. Oposicionista por natureza, como várias vezes declarou, tomou a liberdade de atacar abertamente o governo pela falta de coordenação na luta contra a pandemia. Os argumentos eram tão fortes que provocaram reação imediata do Correio Paulistano. Os ataques dos editorias do Estado preocuparam Julio Mesquita, mas nada pôde fazer, também estava fora de combate. Lobato teve, então, liberdade total para apontar a incompetência das autoridades. O autor de Urupês conta essa história em artigo de 1945. Ao recordar os fatos, o então célebre escritor faz uma bela homenagem ao $O$ Estado de São Paulo:

Tão grande a identidade de todos com a alma do jornal, tamanha a confiança recíproca, que, sem ordem de ninguém, dois meros filantes de café assumem o comando do maior jornal do Brasil e dirigem-no autocraticamente por mais de uma quinzena. E, finda a "ocupação", os donos e gerentes de nada se queixam, antes agradecem a lembrança e perdoam, sorrindo aquela intrusão inédita nos anais da imprensa. Porque nunca, jamais, em país nenhum do mundo, ocorreu uma coisa semelhante ${ }^{3}$.

\footnotetext{
${ }^{2}$ Conforme o próprio Lobato explica, trata-se do sujeito que frequenta a redação para conversar.

${ }^{3} \mathrm{O}$ artigo foi reproduzido no próprio jornal O Estado de São Paulo 6 de abril de 2020 "Especial”, p. H5.
} 


\section{CRÍTICO DE ARTE}

A primeira contribuição de Lobato para um jornal grande saiu em 1913 para o Correio Paulistano -uma crítica a respeito da artista Guiomar Novaes. Escreveu sobre artes, igualmente, para a Folha da Noite. Para este diário, redigiu, entre outros textos, o artigo "As quatro asneiras de Brecheret" (16 de abril de 1921). Logo nas primeiras linhas lemos: "Brecheret é um escultor que apesar de moço já tem na vida uma série de asneiras colossais” (LOBATO, 1957, p. 187). Em seguida, o crítico passa a enumerar as "asneiras" do escultor: ter nascido no Brasil; acreditar que em nosso país incentivariam seu talento; confiar na credibilidade de nossos concursos e não ter exposto sua obra "Eva" logo que chegou a São Paulo. Os elogios ao premiado escultor vinham acompanhados de alfinetadas nos bastidores dos eventos artísticos, sobretudo aqueles ocorridos sob a égide do governo: "Em matéria de arte procede-se no Brasil da mesma forma que em matéria de política, e tudo depende da cavação e da gorjeta, motivo pelo qual a vitória, vira e mexe, cai sempre nas unhas dos comendadores." (Idem, p. 187).

Como crítico de arte, Lobato preza pelas criações genuinamente nacionais, sem laivos de culturas estrangeiras, sem a ascendência das escolas europeias que transformavam nossa arte em mero arremedo dos grandes nomes do outro lado do Atlântico. Não por acaso, o livro Ideias de Jeca Tatu, no qual constam muitas críticas de arte originalmente publicadas em jornais, traz a dedicatória "A Martim Francisco, personalidade feita homem, este grito de guerra contra o macaco". (LOBATO, 1957, p. 1).

Para a Revista do Brasil ${ }^{4}$, Lobato escreveu sobre os pintores Pedro Américo (18431905), Almeida Junior (1850-1899) e Pedro Alexandrino (1856-1942) Nas páginas de O Estado de São Paulo, os leitores descobriram que além de um jornalista atento às questões políticas, sanitárias, econômicas e sociais, vislumbrava-se um crítico de pintura, escultura, teatro e cinema.

\footnotetext{
${ }^{4}$ Renata Rufino da Silva assinalou as críticas sobre artes que Lobato fez para a Revista do Brasil. A autora mostra, ainda, como a produção do pré-modernismo foi negligenciada durante muito tempo. Contudo, os anos que antecederam a Semana de 22 mostraram grande inquietação artística e intelectual. (V. ““'Monteiro Lobato e a Revista do Brasil (1916-1925): representações da ciência, literatura, arte e história". Anais do XXVI Simpósio Nacional de História. ANPUH- São Paulo, julho de 2011, p. 116.
} http://www.snh2011.anpuh.org/resources/anais/14/1300666284_ARQUIVO_RenataRufinotextoanpuhsp disponível em 8 de dezembro de 2020. 


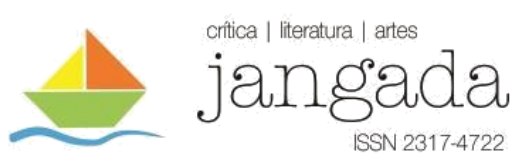

$\mathrm{O}$ artigo que causou mais polêmica e ainda desperta interesse, além de acender debates calorosos dentro e fora do meio acadêmico é "Paranóia ou mistificação: a propósito da Exposição Malfati” publicado em O Estado de São Paulo em 20 de dezembro de 1917. Desde então sucederam-se repercussões negativas. Em 1942, ao fazer um balanço sobre o movimento modernista, Mário de Andrade afirmou:

Ora no Rio malicioso, uma exposição como a de Anita Malfatti podia dar reações publicitárias, mas ninguém se deixava levar. Na São Paulo sem malícia criou uma religião. Com seus Neros também...O artigo "contra" do pintor Monteiro Lobato, embora fosse um chorrilho de tolices, sacudiu uma população, modificou uma vida. (ANDRADE, 2002, p. 259)

Durante décadas, o artigo de Lobato foi interpretado como agressivo, fruto de sua frustração como pintor, pois ele nada entenderia do assunto. Trabalhos acadêmicos lançaram nova luz à questão. Tadeu Chiarelli estudou a atuação de Lobato como crítico de artes plásticas entre 1915 e 1919 em O Estado de São Paulo e elucida-nos a respeito de sua competência como crítico de artes. Para Chiarelli, houve um processo de desautorização feito pelos futuros modernistas, após o episódio de 1917. Lobato foi responsabilizado pelo recuo da artista em relação à modernidade. Malfati, no entanto, já mostrava alguns valores tradicionais da pintura em suas obras. Isso ocorreu igualmente com outros pintores porque logo depois da Primeira Guerra Mundial, muitos artistas distanciaram-se dos ideais das vanguardas, em um processo que depois denominariam "Retorno à ordem". Entretanto, admitir uma mudança de proposta em nossa primeira artista moderna seria pouco conveniente para a construção da chamada "história ideal do modernismo". Chiarelli sustenta que acusar Lobato de algoz de Malfati e desautorizá-lo como crítico foi a saída encontrada por Mário de Andrade, Menotti del Picchia, Sérgio Milliet e Mário da Silva Brito.

Chiarelli elucida as teses lobateanas por meio de uma análise minuciosa de várias críticas publicadas em $O$ Estado de São Paulo e na Revista do Brasil e conclui que o futuro autor de Negrinha era, na arte paulistana, um dos críticos mais competentes. A preocupação em valorizar o homem do campo e as nossas origens estava na base de seus comentários e era coerente com sua posição de defesa da regeneração nacional. 


\section{UM LEITOR CRÍTICO DE JORNAIS}

Lobato sempre foi um grande leitor de jornais. Em 2 de dezembro de 1908, cansado da vida de promotor público ocioso no interior paulista, escreve a Rangel:

Para neutralizar esta Areias sem apito tomei uma assinatura do Weekly Times de Londres - edição semanal em que vêm os melhores artigos do The Times diário, o grande, o velho, o tremendo Times de Londres- e com os pés na grade da sacada injeto-me de inglês, de pensamento inglês, de política inglesa, enquanto pela rua passam os bípedes que vão mexer a panelinha da política local na farmácia do Quindó, meu vizinho. (LOBATO, 2010, p. 187)

Também lia muito os periódicos nacionais, no início de sua correspondência com Rangel, Lobato tece várias críticas aos textos dos jornais. Um dos critérios empregados para sua análise era a quantidade de adjetivos presentes. Por exemplo, em carta de 19 de agosto de 1905, lemos:

\footnotetext{
Nos grandes mestres o adjetivo é escasso e sóbrio- vai abundando progressivamente à proporção que descemos a escala dos valores. Um jormalistazinho municipal, coitado, usa mais adjetivos no estilo do que Pilogênio na caspa. (LOBATO, 2010, p. 95-96)
}

Em carta a Rangel de 7 de julho de 1909, Lobato tece um comentário incisivo contra o estilo empregado nos jornais:

Euclides da Cunha foi um grande ledor de léxicos. Nos Sertões eu notei como ele fugia à vulgaridade sem cair no abstruso, por meio do emprego de palavras que o jornalismo não estafou (porque a cachamorra que achata todas palavras da língua é sempre o jornalismo). (LOBATO, 2010, p. 207)

Em entrevista concedida ao jornal Correio Paulistano a respeito do uso da beca na Academia Paulista de Letras, na verdade, mais uma crônica bem humorada do que entrevista, Lobato concorda com a participação, por escrito, desde que não fizessem nenhuma alteração no Jangada | nr. 16, jun/dez, 2020 | ISSN 2317-4722 72 | P á g i n a 


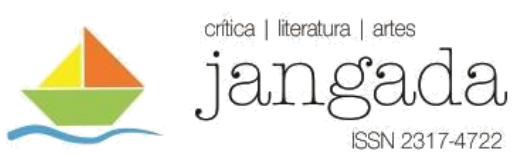

texto que enviaria: “[...] não tem confiança na fidelidade dos jornalistas no apanhar o seu pensamento. E além disso faz a seguinte recomendação: 'Aí vai a entrevista como me saiu ao correr da máquina. Faça o obséquio de dizer ao revisor que dispenso a colaboração dos tipógrafos". (LOBATO, 1946 a, p. 253)

Lobato também destila seu fel contra a banalidade de muitos termos utilizados à exaustão pelos jornalistas que escreviam, muitas vezes, sem criatividade, sem inovações, por meio de uma língua de "toda gente". Em outra carta ao escritor mineiro, datada de 12.02. 1915, Lobato criticará, dessa vez, o caráter sisudo de muitos jornalistas de O Estado de São Paulo:

Ando meio enjoado do Estado, daquela gravidade conselheiral. Eles se têm como o umbigo do universo; num necrológio ou notícia qualquer, pesam numa balança de farmácia o adjetivo a dar ao sujeito - "distinto", "notável”, "conceituado" - e há neles a convicção de que se não deram ao sujeito o adjetivo matematicamente certo, Sírius pisca lá em cima e pode nascer uma lêndea na Cabeleira de Berenice. (LOBATO, 2010, p. 308)

\section{CRÍTICO DE LITERATURA}

Como crítico de literatura, Lobato ressaltava o estilo. Para ele, cada artista precisaria apurar uma forma original de ver o mundo, procurando desvencilhar-se da tentação de copiar os mestres. Era fundamental ler grandes autores não para imitá-los, mas para extrair-lhes o sumo. Em seu artigo "Uma questão de estilo", publicado pela primeira vez no O Estado de São Paulo em 25 de janeiro de 1917, lemos uma bela passagem em que mostra como o poeta Olavo Bilac criou algo novo inspirando-se em clássicos da literatura:

O poeta, no entanto, ao compor o "Caçador de Esmeraldas" não tomou de Corneille um vocábulo, nem de Anatole um conceito, nem de Musset uma noite, nem de Rostand um galo, nem de Lecomte uma frialdade, nem da Grécia um acanto, nem de Roma uma virtude. Mas, sem o querer, pelo fato de ser um moderno aberto a todos os ventos, tomou de Corneille a pureza da língua, de Musset a poesia, de Lecomte a elegância, da Grécia a linha pura, de Roma a fortidão d'alma- e com o antigo-bruto fez o novo-belo. (LOBATO, 1957, p. 33) 
Também em 1917, escreve sobre Nós de Guilherme de Almeida para a revista Paraíba de Caçapava e ressalta a originalidade da obra aproveitando para espinafrar uma corrente literária que ainda encontrava muitos adeptos: “Que delícia não é seguir com o pensamento os estádios do poema Guilhermino sem tropeçar uma só vez num tronco de coluna dórica, ou esbarrar com um centauro em desapoderado corcoveio empós de fugitiva ninfa!" (LOBATO, 1964, p. 72).

Apesar de nunca ter escrito um livro de crítica de literatura, os artigos dispersos em diferentes jornais e revistas revelam um leitor arguto, preocupado em respeitar as mais diversas pesquisas estéticas.

O revolucionário do mercado editorial no Brasil colaborou também para jornais estrangeiros. Em "Eu tomo o Sol..." publicado no jornal argentino La Prensa, discorre sobre o trabalho árduo dos tradutores: "Para o tradutor não haverá nunca remuneração econômica, nem glória, nem sequer a gratidão dos homens; só há insultos quando não faz o trabalho perfeito" (LOBATO, 1964, p. 237). Lobato elogia a tradução para o espanhol que Benjamin de Garay faz de Os Sertões de Euclides da Cunha. Comenta, da mesma forma, o imenso prazer que sentiu ao traduzir para o português Madame Curie, biografia escrita por Eva Curie, filha da cientista. No começo desse artigo, emprega uma bela imagem para representar o trabalho dos tradutores: "O tradutor é um escafandrista. Mergulha na obra como num mar; impregna-se dum pensamento concretizado de um certo modo- o estilo do autor- e lentamente o vai moldando no barro de outro idioma, para que a obra não admita fronteiras.” (LOBATO, Idem, p. 37)

A envergadura do autor de Cidades mortas como crítico literário em seus artigos para a imprensa vislumbra-se, sobretudo, no ensaio "Machado de Assis" escrito também para o La Prensa em 1939, ano do centenário de nosso maior romancista.

Antes de comentar a obra, Lobato lembra a origem humilde do escritor e aproveita para trazer à tona a questão da desigualdade social no Brasil, atrelada, via de regra, ao racismo:

Joaquim Maria Machado de Assis. Um "pardinho". Era com este nome que as orgulhosas marionettes de tez branca denominavam pejorativamente os filhotes das marionettes de pele pigmentada. A pele pigmentada estava em desfavor, por ser característica dos homens primitivos que os brancos caçavam nos Kraals africanos, para metê-los no trabalho duríssimo da cana de açúcar 
ou do café. Negros. O negro misturado com o branco dava o pardo. (LOBATO, 1946, p. 331).

Lobato enfatiza também o caráter autodidata de Machado e os trabalhos braçais que fez quando adolescente para ajudar a família. O jovem aproveitava sempre que possível para aprimorar seu conhecimento. Em uma passagem digna de nota, refere-se com deferência a um dos trabalhos críticos até hoje considerados fundamentais para entender o autor de Dom Casmurro:

Talvez o mais luminoso espírito da crítica no Brasil, uma mulher, Lucia Miguel Pereira, publicou sobre ele, há três anos, um livro. Trezentas e quarenta páginas espelhantes. A mais alta realização indígena em matéria de análise literária- uma lição de mulher aos homens. Não há estudo biográfico menos enriquecido de anedotas, menos policial, menos sensacionalista- nem mais empolgante. (Idem, p. 333).

Ao abordar as primeiras publicações do romancista carioca, Lobato observa que o autor não havia, ainda, criado algo novo: "O medo de inovar, de exceder-se, de dizer demais, tira qualquer interesse aos seus primeiros romances [...]" (Idem, p. 333). De fato, hoje existe quase um consenso a respeito da diferença que separa seus primeiros romances e as obras-primas que nos legou. Mais uma vez, Lobato enfatiza sua aversão à opulência vocabular. Aliás, em sua correspondência com Rangel, com frequência comenta a preocupação de autores menores em exibir vocabulário variado e complexo. Machado mostra-nos o contrário:

Machado de Assis ensinou o Brasil a escrever com limpeza, tacto, finura, limpidez. Criou o estilo lavado de todas as douradas pulgas do gongorismo, do exagero, da adjetivação tropical, do derramado, da enxundia, da folharada intensa que esconde o tronco e o engalhamento da árvore. (LOBATO, Idem, p. 334)

Os contos de Machado merecem destaque para o Lobato crítico, considera-os exemplos de fatura e de densidade filosófica. Sem similares em língua portuguesa, compara o escritor brasileiro a um dos mais importantes nomes franceses do século XX: 
Temos de correr à França para em Anatole France encontrarmos um seu irmão. Este, entretanto, desabrochou no mais propício dos canteiros- amimado por uma alta civilização, estimulado por todos os prêmios, rodeado de todos os requintes do conforto e da arte. Já o pobre Machado de Assis só teve como ambiente um sórdido Rio colonial, e prêmio nenhum afora a sua aprovação íntima, e parquíssima renda mensal para a subsistência; e como leitores, nada do mundo inteiro, que era o leitor de Anatole - mas apenas meia dúzia de amigos. (Idem, p. 335)

Enumerando os contos que mais aprecia, Lobato lamenta o fato de nosso idioma não gozar de prestígio algum: “Ah, se a língua portuguesa não fosse um idioma clandestino...” (Idem, p. 336).

Se o crítico de artes plásticas foi desprestigiado pela "história ideal do modernismo", a relevância do crítico de literatura permaneceu pouco estudada por muitas décadas. Uma lacuna explicável por que seus trabalhos sobre o tema estão dispersos em diferentes periódicos e publicados em livros menos conhecidos do autor como Prefácios e Entrevistas de 1946.

\section{CONSIDERAÇÕES FINAIS}

Mais de setenta anos após a morte de Monteiro Lobato, sua obra tem sido reeditada, discutida e revista. Suas contribuições para os periódicos nacionais e estrangeiros ainda constituem um corpus relativamente pouco explorado, a despeito de trabalhos acadêmicos dedicados à questão. A sinceridade com que Lobato exprimia suas opiniões, sem rebuços e com a coragem de assumir posições polêmicas lhe valeram muitos desafetos. Não por acaso, até hoje há ainda quem o considere "nacionalista empedernido", algoz de Anita Malfati e crítico sem instrumentalização conceitual.

É mister abandonarmos os preconceitos e voltarmos nosso olhar para as crônicas e artigos que redigiu. A partir dessa análise e levando sempre em consideração o conjunto de sua obra, os percalços que enfrentou, o ambiente em que produziu e os princípios que o nortearam, poderemos, então, vislumbrar não a "história ideal", mas sim a história real da literatura brasileira. 


\section{REFERÊNCIAS BIBLIOGRÁFICAS}

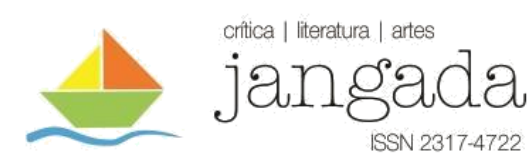

ASSIS, Francisco de. Monteiro Lobato na Imprensa. In: Matrizes, n ${ }^{\circ} 2$ jul./dez 2014 p. $297-$ 311.

BECKER, Elizamari Rodriguez. Forças motrizes de uma contística pré-modernista: o papel da tradução na obra ficcional de Monteiro Lobato. Tese de Doutorado em Literatura Comparada, defendida na UFRGS. Porto Alegre, 2006, disponível em 8 de dezembro de 2020 https://www.lume.ufrgs.br/bitstream/handle/10183/7650/000550655

BEDÊ, Ana Luiza Reis. Monteiro Lobato e a presença francesa em a Barca de Gleyre. São Paulo: FAPESP/ Annablume, 2007.

. Os intermúndios literários de Monteiro Lobato e Godofredo Rangel em A Barca de Gleyre. In: Teresa, [S. l.], n. 8-9, p. 130-140, 2008. Disponível em: https://www.revistas.usp.br/teresa/article/view/116696. Acesso em: 15 dez. 2020.

CAMARGOS, Marcia. (org.). Juca e Joyce: memórias da neta de Monteiro Lobato. Depoimentos de Joyce Campos Kornbluh a Marcia Camargos. São Paulo: Moderna, 2007. CAVALHEIRO, Edgar. Monteiro Lobato: vida e obra. (2 vol.) São Paulo: Brasiliense, 1962. CHIARELLI, Tadeu. Um Jeca nos vernissages. São Paulo: Edusp, 1995.

LAJOLO, Marisa. (Org.). Monteiro Lobato, Livro a Livro: Obra adulta. São Paulo: editora Unesp, 2014.

MONTEIRO LOBATO. A Barca de Gleyre. São Paulo: Editora Globo, 2010. . Conferências, artigos e crônicas. São Paulo: Editora Brasiliense, 1964. . Ideias de Jeca Tatu. São Paulo: Editora Brasiliense, 1957. . Mundo da Lua e Miscelânea. São Paulo: Editora Brasiliense, 1946.

PAGNOLI, C. R. de A. (2018). Godofredo Rangel leitor: memórias literárias na correspondência trocada com Monteiro Lobato. In: Teresa, 1(19), 249-264. Disponível em 3 de dezembro de 2020 https://doi.org/10.11606/issn.2447-8997.teresa.2018.146109

SILVA, Renata Rufino da. Monteiro Lobato e a Revista do Brasil (1916-1925): representações da ciência, literatura, arte e história. In: Anais do XXVI Simpósio Nacional de História. ANPUH- São Paulo, julho de 2011, pp. 1-16.

http://www.snh2011.anpuh.org/resources/anais/14/1300666284_ARQUIVO_RenataRufinote xtoanpuhsp disponível em 8 de dezembro de 2020. 
VALENTE, Thiago Alves. Monteiro Lobato nas páginas do jornal: um estudo dos artigos publicados em O Estado de São Paulo (1913-1923). São Paulo: Editora Unesp, 2010

FUNDAMENTOS: revista de cultura moderna. São Paulo. Setembro-Outubro 1948. № 5 e 6 , Vol. II. (é neste artigo que há a citação de Schimidt )

Disponível em http://memoria.bn.br/pdf/102725/per102725_1948_00004-00005. Consultado em 06 de outubro de 2020. 